\title{
El imaginario social de la acción colectiva de protesta y la crisis Argentina de 2001, en el discurso de la prensa en Chile ${ }^{1}$
}

\author{
Alberto Javier Mayorga Rojel
}

Universidad de La Frontera, Temuco, Chile. Email: amayorga@ufro.cl

\author{
Carlos del Valle Rojas
}

Universidad de La Frontera, Temuco, Chile. Email: delvalle@ufro.cl

\section{Rodrigo Browne Sartori}

Universidad Austral de Chile, Valdivia, Chile. Email: rodrigobrowne@uach.cl

Resumen: En el presente trabajo se procede a la entrega de los resultados de una investigación acerca de los imaginarios sociales producidos por la prensa en un contexto específico que corresponde a la crisis argentina de 2001, y, a su vez, procura contribuir empíricamente a la discusión acerca del poder que ostenta la prensa escrita en contextos de conflicto social.

Palabras claves: Imaginarios sociales, Medios de comunicación, Crisis Argentina de 2001, Análisis del discurso.

\section{The social imaginary of collective protest and Argentinean crisis in 2001, in the chilean press discourse}

Abstract: In this paper we proceed to present the results of an investigation about the social imaginaries constructed by the press in a specific context that corresponds to the argentinean economic crisis in 2001, and also seeks to contribute empirically to the discussion about the power of media in contexts of social conflict.

Key words: Social Imaginaries, Mass media, Argentinean 2001's crisis, Discourse analysis.

\section{O imaginário social sobre a ação coletiva de protesta ea crise na argentina comunicado pela imprensa do chile 2001}

Resumo: Neste artigo, proceder para entregar os resultados de uma investigação das imagens sociais produzidas pela imprensa em um contexto específico que corresponde à crise na Argentina em 2001, e, por sua vez, busca contribuir para a discussão empiricamente o poder que detém os meios de comunicação em contextos de conflito social. 
Palavras-chave: Imaginário Social, Mídia, crise da Argentina de 2001, análise do discurso.

\section{Introducción}

En la actualidad no podemos negar que los medios de comunicación son parte fundamental de las sociedades modernas que existen en el mundo y el caso de Latinoamérica no es una excepción. Por tal razón, es posible afirmar que somos testigos privilegiados de un espacio-tiempo donde los avances tecnológicos que han impactado el quehacer de las diversas empresas periodísticas, en términos de la cantidad de informaciones que son capaces de producir, reproducir y transmitir a las audiencias a nivel global mediante el libre acceso a sus plataformas informativas de carácter digital, deben ser comprendidos como un factor central que explica la relevancia social que poseen hoy los diversos componentes del sistema de medios de información y comunicación tanto en nuestro continente como en el resto del mundo.

A este respecto conviene subrayar que los medios de comunicación como es el caso de la prensa, radio y televisión, utilizan las múltiples plataformas de redes sociales para obtener información acerca de los hechos que ocurren en el espacio público. Sin embargo, a pesar del aumento en el uso de las redes sociales por parte de los usuarios, aún los medios de comunicación son utilizados por la mayoría de las audiencias para informarse acerca de lo que ocurre en su entorno y, por tanto, estos medios de comunicación mantienen un rol preponderante en la visibilización y explicación de los acontecimientos que ocurren al interior del escenario político y económico que se estructura en América Latina. Por ello, si los medios de comunicación tradicionales siguen siendo los dispositivos de mayor relevancia e impacto en la conformación de la opinión pública, entonces las audiencias que consumen los mensajes producidos, reproducidos y transmitidos por estos medios de comunicación, suelen disponer de un conjunto de esquemas de interpretación que se instauran desde los dispositivos mediáticos tradicionales con la intención de legitimar sus posiciones y establecer una consonancia con las audiencias.

Considerando lo dicho, vale la pena establecer que los medios de comunicación son un recurso fundamental para el funcionamiento de todo sistema social y, además, son utilizados por diversas instituciones que las emplean en la medida que reconocen su capacidad de mediación en la vida de millones de personas que consumen a diario productos informativos que se elaboran sobre la base de un conjunto de sedimentos ideológicos e imaginarios sociales que son compartidos por los miembros de la sociedad en la medida que logran cristalizar un conjunto de significaciones en torno a un mundo posible y sus particularidades políticas, económicas, sociales y culturales. 
De hecho, los medios de comunicación han sido los encargados de diseminar un conjunto de informaciones y opiniones acerca de los conflictos sociales que se han articulado en el espacio público latinoamericano producto de las demandas ciudadanas focalizadas en la insatisfacción por el modelo de desarrollo económico implementado en varios países latinoamericanos, la carencia de sistemas políticos participativos que promuevan un tipo de democracia más inclusiva, la sistemática profundización de la desigualdad en lo que respecta a las lógicas de distribución de los ingresos, los recortes presupuestarios producto de las crisis económicas, precarización de los sistemas de salud y educación pública, falta de participación efectiva en la toma de decisiones gubernamentales, entre otros y variados temas. Por tanto, los conflictos sociales que germinan producto de las múltiples crisis del sistema económico global como de los sistemas políticos nacionales, conllevan un conjunto de acciones colectivas de protesta que son ejecutadas por los sujetos sociales con la finalidad de visibilizar sus demandas en el espacio público. En este sentido, las movilizaciones sociales son una expresión pública de las demandas e intereses de un colectivo social que pueden lograr una ruptura del orden establecido, lo que de forma inmediata atrae la atención de los medios de comunicación con la finalidad de realizar las coberturas pertinentes de los acontecimientos que se enmarcan bajo el rótulo de protesta social para, posteriormente, generar la producción de un conjunto de discursos periodísticos portadores de significaciones imaginario sociales.

Desde este punto de vista, las significaciones imaginario sociales que cristalizan los medios de comunicación por medio de la producción de discursos periodísticos, específicamente en el terreno de los conflictos sociales donde nos interesa comprender la construcción socioimaginaria que la prensa de Chile elabora acerca de las movilizaciones sociales gestadas por los colectivos de ciudadanos, están centradas en principios hegemónicos que buscan mantener un sistema ordenado de referencia dominante asentado en mapas ideológicos capaces de determinar la construcción significativa de un mundo posible, lo que produce, a su vez, un control discursivo sobre todo conflicto social como mecanismo productor de esquemas interpretativos o marcos de referencias capaces de facilitar a las audiencias un tipo de distinción dicotómica.

Por ello, estimamos que nuestro trabajo es un aporte al campo de las investigaciones en las ciencias sociales en la medida que promueve las indagaciones acerca de la producción de significaciones imaginario sociales por parte de la prensa en contextos de conflicto social. No obstante, en esta oportunidad nos focalizamos en el análisis de la producción socioimaginaria del diario El Mercurio (Chile) respecto de las acciones colectivas de protesta gestadas en la Argentina durante la crisis del 2001. Importante es resaltar que las acciones colectivas de protesta se producen al interior de una sociedad civil fragmentada producto de las políticas de ajustes económicos de corte neoliberal que se aplicaron tanto en el país trasandino como -de manera heterogénea- en los distintos países de América Latina. De la misma manera, vale reiterar que nuestro trabajo de investigación apunta a des- 
cribir los imaginarios sociales que son construidos por la prensa en torno a la expresión visible de un colectivo social determinado por un contexto que identificamos como democrático representativo, en lo político, y neoliberal, en lo económico, de tal forma que debemos tener absoluta claridad que el conjunto de discursos generados por la prensa sobre las acciones colectivas de protesta ocurridas en la Argentina durante la crisis del 2001, no están únicamente constituidos a partir de determinados relatos y opiniones que se sustentan en abstracciones complejas de sentido sino que, además, este conjunto de discursos configura su legitimidad mediante una intertextualidad asociada a los hechos ocurridos en el pasado y que se complementan en el presente con una secuencia de acciones políticas llevadas a cabo por las autoridades del gobierno argentino de la época.

Pues bien, una vez declarado nuestro objeto de estudio podemos destacar que los acontecimientos de movilización social que se gestaron en varias provincias de la República Argentina durante el 2001, no estuvieron exentas de la respectiva cobertura mediática, lo que permitió la circulación masiva de discursos periodísticos que articularon las lógicas de consumo por parte de los miembros de la sociedad global. En este cometido, los medios de comunicación, desde una perspectiva habermasiana de las legitimaciones, pueden ser comprendidos como los engranajes de un sistema de información global que determina la configuración de sentido de un conjunto de imágenes y acontecimientos con el propósito de legitimar la existencia misma del sistema de medios de información y comunicación global y, en consecuencia, mistificar la descripción y explicación de un acontecimiento que posee una visibilidad pública mediante la intervención de sujetos y actores sociales movilizados en virtud de una demanda colectiva (Habermas, 1999).

En este sentido, nos parece de vital importancia recalcar que los medios de comunicación, en general, y la prensa, en particular, poseen la capacidad de proveer a las audiencias de un mensaje que contempla un mapa conceptual capaz de ordenar, clasificar y organizar los hechos y conflictos que involucran a múltiples sujetos, actores sociales e instituciones gubernamentales, dentro de un contexto referencial apropiado para promover un sentido socialmente aceptado por la mayoría. Es decir, siguiendo a John B. Thompson (1998: 56) y su concepto de experiencia mediática, podemos pensar que los medios de comunicación, como en el caso de la prensa, tienen la capacidad de configurar las experiencias de las audiencias lo que inevitablemente marca un quiebre en la frontera de las percepciones que el individuo tiene a partir de sus contactos cotidianos e inmediatos, para dar paso a una nueva realidad mediatizada por un elemento técnico (radiotransmisor, diarios, televisor, computador y celular), donde las formas simbólicas que se acuñan en el conjunto de discursos producidos por los medios de comunicación proporcionan las significaciones imaginarios sociales que se transforman en el sustento para la producción o reproducción de un imaginario social de las acciones colectivas de protesta desencadenadas durante la crisis argentina del 2001. 
De hecho, si visualizamos a la prensa como un recurso/tecnología que facilita la masificación de un conjunto de discursos periodísticos acerca de algo o alguien, entonces toda experiencia mediática conlleva una apropiación/aceptación o rechazo/negación de imaginarios sociales. En tal sentido, los imaginarios sociales que se expresan a través de las formas simbólicas acuñadas en el conjunto de discursos periodísticos producidos por la prensa, permiten la construcción de un saber colectivo y compartido, lo que -además- articula una construcción social de la realidad donde se logran legitimar significaciones, visiones de mundo y opiniones. Es por tal razón que desde la perspectiva de Manuel Antonio Baeza (2003: 20) "los imaginarios sociales son múltiples y variadas construcciones mentales (ideaciones) socialmente compartidas de significancia práctica del mundo, en sentido amplio, destinadas al otorgamiento de sentido existencial”. En otras palabras, los imaginarios sociales ordenan la vida cotidiana y dan sentido al mundo que nos rodea, por lo tanto, "no hay posibilidad alguna de utilización del concepto de imaginarios sociales sin la idea consustancial de institucionalización social de determinadas visiones, de determinados discursos y de determinadas prácticas con efectos sociales y, por último, hasta de determinados estilos de la acción social” (Baeza, 2008: 190).

Por ello, valoramos la posibilidad de aportar al ámbito específico de los estudios del discurso de la prensa y los imaginarios sociales en contextos de conflicto social y, a su vez, profundizar empíricamente en la discusión acerca del poder que ostentan los medios de comunicación, en general, y la prensa, en particular. Incluso, podemos precisar que nuestro trabajo centra su atención en el análisis del discurso periodístico elaborado por el diario El Mercurio de Chile, el cual posee una relevancia y legitimidad en lo que respecta a la conformación de la opinión pública producto del reconocimiento que los actores más influyentes de la política y la economía de Chile le han otorgado. Además, en términos de criterios utilizados para su selección como unidad de información principal, podemos destacar que el diario El Mercurio está directamente ligado a los grupos conservadores, católicos y empresariales del país, posee una amplia cobertura nacional e internacional, este último punto se justifica mediante la presencia de este periódico en el Consorcio Grupo de Diario América, y, finalmente, es factible indicar que según los datos proporcionados por el Sistema de Verificación de Circulación y Lectoría (2011, 1er Semestre), en la cual participan la Asociación Nacional de Avisadores (ANDA), la Asociación Chilena de Agencias de Publicidad (Achap) y los principales diarios pagados y gratuitos del país; el diario El Mercurio cuenta con un promedio de 409.949 lectores semanales donde se considera tanto el consumo de la versión impresa y digital del diario.

Por último, es preciso tener en cuenta que nuestra intención no es desarrollar una descripción histórica detallada de los sucesos económicos, políticos y sociales que afectaron a la Argentina entre los años 1990 y 2001. Incluso, en rigor el presente trabajo no pretende explicar las causas o determinar las consecuencias que provocaron -en diversas áreas del desarrollo de la Argentina- la crisis institucional y la movilización de las fuerzas so- 
ciales en distintos puntos geográficos del mencionado país. Sino más bien nuestro trabajo se focaliza, por una parte, en describir los imaginarios sociales producidos por la prensa en un contexto específico que corresponde a la crisis argentina de 2001, aportar al ámbito de los estudios del discurso de la prensa y los imaginarios sociales en contextos de conflicto social y, a su vez, contribuir empíricamente a la discusión acerca del poder que ostentan los medios de comunicación, en general, y la prensa, en particular. Y, por otra, se busca sistematizar el uso de un modelo de análisis del discurso periodístico diseñado e implementado en instancias investigativas elaboradas por académicos del Grupo de Investigación en Comunicación y Saberes Críticos de la Universidad de La Frontera, a saber: 1) proyecto FONDECYT N¹100264, 2) Proyecto FONDECYT N 1120904 y 3) Proyecto DIUFRO $\mathrm{N}^{\circ}$ DI120060. Por cierto, esperamos que lo declarado permita al lector identificar con claridad la problemática central de nuestro trabajo y reconocer, también, los límites de nuestra investigación.

\section{Contexto del estudio: antecedentes en torno a la acción colectiva de protesta en el marco de la crisis argentina de 2001}

Para comenzar esta sección del trabajo asociado al contexto donde se enmarca nuestra problemática, creemos necesario consensuar que las transformaciones políticas, económicas y sociales que han acaecido en Latinoamérica, en general, y en el caso Argentino, en particular, producto de la aplicación de reformas estructurales asociadas a la implementación del modelo neoliberal, han conducido a varios países del continente por una vía del desarrollo marcada por nuestra condición de países exportadores de materias primas, por una lógica de libre mercado y apertura de nuestras fronteras económicas, como única forma utilizada para fomentar un crecimiento sostenido en el tiempo sobre la base de un aumento de la inversión extranjera, reestructuración de los modos de producción y consumo, control de los índices inflacionarios y, por supuesto, compromiso total con el pago de la deuda externa.

Sin embargo, desde la perspectiva de Osvaldo Iazzetta:

“En suma, estas reformas no resultaron neutras en términos de poder económico y social. El reemplazo de monopolios estatales por otros privados que ocasionó el proceso de privatizaciones creó un nuevo polo de poder que reúne una enorme capacidad reguladora sobre mercados decisivos. Asimismo, la entronización del mercado como máxima instancia de coordinación, sometió a sus reglas la distribución de bienes públicos (salud, educación y seguridad social), convirtiendo en bienes mercantiles lo que antes se reconocía como derechos ciudadanos” (Iazzetta, 2007: 99-100).

En este contexto, los acontecimientos acaecidos en la Argentina en 
diciembre de 2001, donde diversas organizaciones sociales y formas de movilización política se expresaron contra el modelo económico y político vigente hasta ese periodo, serán comprendidos a partir de la noción de acción colectiva de protesta. Este concepto da cuenta de una dinámica de resistencia en el espacio público argentino donde los sujetos sociales mediante un repertorio de protesta de acción colectiva apuntaban a visibilizar sus demandas contra el modelo neoliberal y el rechazo frente a los altos niveles de corrupción del sistema político y el repudio a la represión policial ejercida en las calles de las ciudades más importantes del país trasandino.

Es decir, en palabras de Favaro, Iuorno y Cao:

"La crisis de 2001 agudiza los conflictos que provocan el traspaso de la empresa pública a manos privadas, con la consiguiente expulsión de mano de obra, precariedad de trabajo, incapacidad de los políticos para resolver los problemas de la sociedad y un Estado que, como el neuquino -controlado por un grupo de sectores burgueses, aliado a las petroleras-, también muestra una faceta poco conocida tiempo atrás: la corrupción” (Favaro, Iuorno y Cao, 2006: 107).

En este sentido, los sucesos de diciembre de 2001 en Argentina serían la manifestación evidente de un quiebre entre las instituciones representativas del Estado y el poder económico con la sociedad civil y los sujetos sociales adscritos a las clases medias y a los sectores de piqueteros (desempleado); este último corresponde al concepto que articula el devenir de aquellos individuos que son excluidos del entramado laboral diseñado por el modelo neoliberal e implementado por el mundo privado y el Estado, y que sufren las consecuencias del no reconocimiento como miembros productivos de la sociedad argentina.

En esta misma dirección, Igor Goicovic considera que:

"Los sectores populares se han construido históricamente en los bordes del sistema. Ello ha determinado que, en general, sus relaciones con el Estado se encuentren permanentemente conflictuadas. Su defensa de la autonomía y de los aspectos esenciales de su identidad social, los han contrapuesto permanentemente con las iniciativas y mecanismos disciplinadores y homogeneizadores desplegados por las clases dominantes y el Estado" (Goicovic, 2000: 120121).

Desde luego este aspecto es controvertido, pero en cierto modo debemos tener claro que esta plataforma neoliberal ha logrado disipar la fuerza del Estado y sus representantes, empobreciendo las dinámicas relacionales al interior del sistema social y la capacidad articuladora del Estado en términos organizacionales. En otras palabras, la globalización en conjunto con el modelo económico neoliberal han promovido cambios en dos dimensiones relevantes del Estado, a saber: 
1) Se debilita su capacidad para organizar a la sociedad, redistribuir equitativamente las riquezas, cohesionar a la ciudadanía a partir de un proyecto común y gestionar la eficiente participación democrática (no meramente instrumental) de la ciudadanía.

2) Se fortalece su papel de interlocutor válido (no interventor) entre el capital internacional y el mercado local, regulador legítimo de las relaciones que se establecen entre los actores del mercado y la sociedad civil, dinamizador de las relaciones internacionales sobre la base de su actuar como un articulador de mecanismos de compenetración económica-política entre los países industrializados y las naciones en vías de desarrollo, y, finalmente, facilitador de las modificaciones necesarias (desregulaciones) para la subsistencia de determinados sistemas productivos y/o cambios de éstos.

Así entonces, el despliegue del poder económico mundial es el resultado de un desgaste del aparato estatal que no puede asegurar una presencia homogénea en todo el territorio. Por tal razón, Ignacio Lewkowicz sostiene que:

"El Estado era el tablero dentro del cual transcurría la existencia de un conjunto de entidades que llamamos instituciones (...). Una de esas instituciones, una pieza de ese tablero, era el mercado liberal. Ese mercado era una laguna en medio de un continente sólido (...). Pero esa laguna crece, se desborda, se desconviene, se vuelve incontenible. Lo llaman neoliberalismo, o tercera ola, o globalización, o algo. [Por consiguiente], esa laguna que era una pieza del tablero estatal se convierte ahora en el tablero de otra lógica [y], a la vez, el Estado que era el tablero, en esta reversión, se convierte en una pieza entre otras” (Lewkowicz, 2006: 176).

Por su parte, y volviendo al contexto de la crisis argentina, tenemos que esta idea del desbarajuste del modelo económico y político que imperaba hasta ese entonces en Argentina se sustenta en que desde "diciembre de 2001 se pone de manifiesto la ruptura del bloque dominante que solventaba la convertibilidad. Las fuerzas ideológicas y económicas que lo expresaban dejan de apoyar a la clase política y el sistema político entra en una de sus más profundas crisis de la democracia desde 1983” (Battistini, 2007: 100).

Considerando lo dicho, vale la pena advertir que el modelo neoliberal articulado durante el gobierno de Carlos Menen en Argentina específicamente mediante la acción de privatizar la mayor cantidad de empresas y servicios públicos - y que contó con el apoyo estratégico de los grupos financieros internacionales, no ha permitido dar una solución efectiva y mucho menos avanzar en propuestas que apunten a resolver los problemas sociales, económicos y políticos que afectan en la actualidad a la sociedad argentina. Bajo el fracaso de este modelo privatizador y desregulador de los mercados, en el plano económico, impuesto por las dinámicas hegemónicas de los organismos financieros de los países desa- 
rrollados (FMI y Banco Mundial) y, en el plano político-social, el debilitamiento de un campo de acción propio del Estado junto a la despolitización del ejercicio de la ciudadanía, se acentúa la necesidad de identificar y tomar conciencia acerca del sentido actual que posee la ciudadanía y la sociedad civil como elementos centrales para el fortalecimiento de una democracia menos maniatada. Por tal motivo, en el caso de la realidad argentina debemos asumir que la articulación de una contrahegemonía se entiende como un desafío enmarcado dentro de las posibilidades presentes de los miembros de la sociedad civil. Así entonces, las articulaciones (redes activas) que se producen entre los actores sociales mediante los procesos comunicativos y las acciones colectivas de protesta evitan la dispersión de los mismos, potencia su reconocimiento como agentes sociales del cambio y la resistencia, pero no -necesariamente- los aglutina bajo un mismo proyecto político con continuidad en el tiempo.

Ahora bien, conceptualmente, es necesario subrayar que en el caso argentino la protesta social es una herramienta utilizada por los sectores sociales identificados bajo el rótulo de piqueteros como alternativa válida para interpelar al poder estatal sobre la base de una demanda puntual de integración al sistema económico, en virtud de la ausencia de canales formales que faciliten una injerencia en las instancias de toma de decisión gubernamental o instauren un espacio de negociación amparado en el reconocimiento como grupo de poder legitimado por el sistema político nacional. establece que:

Pues bien, a partir de las ideas expuestas por Federico Schuster, se

"La noción de protesta social se refiere a los acontecimientos visibles de acción pública contenciosa de un colectivo, orientados al sostenimiento de una demanda (en general con referencia directa o indirecta al Estado) En este sentido, cabe remarcar que el concepto se limita a partir de su carácter contencioso e intencional, por un lado, y de su visibilidad, por el otro" (Schuster, 2005: 56).

\section{Es por ello que:}

"La protesta, desde la teoría de la acción colectiva, encierra la realidad de una lucha entre dos sujetos por la apropiación y orientación de los valores sociales y de los recursos; no se agota en una sola manifestación, tiene periodos de latencia y explosión; es el recursos de los que no tienen poder o no están representados por formas tradicionales” (Favaro, Iuorno y Cao, 2006: 97).

En tal sentido, nos parece necesario reconocer que la acción colectiva de protesta, a pesar de su carácter coyuntural y contingencial (Schuster, 2005), se establece como una forma de movilización política que se instaura en el espacio público con la finalidad de cuestionar la hegemonía instalada por los grupos dominantes de la sociedad argentina. Esto nos lleva a com- 
prender que la protesta social es una forma de acción colectiva utilizada para la expresión pública de las demandas e intereses de un colectivo social y que, además, logra producir una ruptura del orden establecido. Tal como apunta Scribano y Schuster (2004: 10):

“La protesta social es un modo de ruptura del orden social regular, pero al mismo tiempo puede convertirse en un modo cuasi normal de la práctica política en los márgenes del sistema político. En esa cornisa entre la normalidad y la ruptura camina hoy la protesta social”.

En consecuencia, los actores sociales presentes en la sociedad argentina y que participaron de las protestas sociales de diciembre de 2001 pueden ser incorporados a la matriz conceptual de multitud (Negri y Cocco, 2006), lo que conlleva una comprensión del fenómeno de la protesta social como la suma de subjetividades y singularidades determinantes de una posición contraria a la desvinculación del concepto y el ejercicio, es decir determinantes de la soberanía de los miembros de una sociedad en términos de ciudadanías activas y de su efectiva acción en el plano de las estrategias de lucha producto de sus demandas contra las condiciones de explotación y abuso por parte de los grupos económicos y políticos dominantes. No caben dudas entonces que las acciones colectivas de protesta generadas, por una parte, por miembros de la clase media argentina cuando ocuparon las plazas y espacios públicos urbanos para alzar la voz de un pueblo que perpetuaba el slogan ¡Qué se vayan todos!, y, por otra, cuando hombres y mujeres de las clases populares saqueaban los centros comerciales y marchaban por las avenidas o arterias centrales de los centros urbanos más importantes de Argentina, se transformaron en nuevas formas no convencionales (Auyero, 2004) de resistencia colectiva que aspiraban al derrocamiento de un gobierno o más bien al cambio de la forma de hacer política y de la lógica neoliberal presente desde 1990.

\section{El discurso de la prensa como discurso de poder en el espacio público}

Quisiéramos comenzar por establecer una breve síntesis teórica sobre el concepto de discurso que nos permitirá avanzar en la comprensión de esta práctica social que facilita el funcionamiento del proceso comunicativo y que, además, es una noción fundamental de la presente investigación. De modo que, como aproximación inicial, el discurso se plantea como un objeto dinámico que se hace presente en una acción comunicativa determinada, puesto que involucra a actores sociales que poseen roles establecidos (hablantes y oyentes), que se relacionan en una situación específica, a través de un acto comunicativo determinado por el contexto y que, como consecuencia de la interacción, producen un sentido.

Ahora bien, en el desarrollo de las sociedades modernas, donde se lleva a cabo la producción y difusión de discursos periodísticos a través de 
los diversos dispositivos de comunicación masiva, se hace cada vez más evidente la importancia de los procesos de interacción y apropiación de los mensajes por parte de las audiencias, puesto que el discurso de la prensa, construido sobre la base de un acontecimiento aparentemente particular, se estructura a partir de un conjunto de significaciones socioimaginarias que son reconocidas por los miembros de un grupo social en la medida que se entrelaza con el tejido social de la memoria colectiva y se compenetra con las prácticas culturales, Es en este sentido que el discurso de los medios de comunicación, en general, y de la prensa, en particular, permiten la configuración de relatos y opiniones capaces de acuñar significaciones imaginario sociales acerca de algo o alguien.

En vista de lo anterior, es posible afirmar que en el marco de las lógicas mediáticas establecidas para la cristalización de imaginarios sociales, el discurso de la prensa se visualice como una construcción comunicativa simbólica ya que está determinado por un sistema que posee una forma codificada y contenedora de visiones del mundo. En efecto el discurso es una producción social y como tal es parte de un proceso de interacciones lo que implica una práctica socialmente ritualizada donde los actores sociales confluyen para el intercambio/confrontación de sus realidades y formas de interpretar al mundo. Como puede observarse desde la perspectiva de Siegfried Jäger (2003: 66), "los discursos determinan la realidad siempre a través de sujetos que intervienen activamente en sus contextos societales como (co)productores y (co)agentes de los discursos y cambios de la realidad”.

De hecho, si el discurso de la prensa puede ejercer su poder para estructurar un tipo de mundo posible bajo determinadas condiciones de consumo establecidas para la apropiación de una experiencia mediática, entonces tal situación nos permite asumir la existencia de una intencionalidad por parte de la prensa en lo que respecta a "lo que puede y debe ser dicho" respecto a un acontecimientos. Por tanto, el discurso de la prensa posee un valor especial en la reproducción de una ideología determinada. Esta capacidad que tiene la práctica social del discurso de la prensa facilita la configuración de un campo referencial específico donde los contenidos responden a ciertas significaciones socioimaginarias convenientes para un grupo social.

En efecto, el discurso de la prensa como acción comunicativa y práctica social que se gesta en el sistema de los medios de comunicación a partir de las interacciones en los espacios de conflicto social, corresponde a una plataforma donde se puede elaborar, construir, reforzar o modificar imaginarios sociales a partir de las formas ideológicos vinculadas a determinadas estrategias discursivas como es el caso de la retórica a modo de mecánica persuasiva que busca inocular ciertas nociones positivas (aceptación) o negativas (rechazo) de un fenómeno social. Esta estrategia discursiva sustentada en el plano ideológico dominante existente en toda interacción social produce una concentración de opiniones e imágenes capaces de expresar, indicar o acentuar algunas características de un acontecimiento que 
vayan en directa relación con la intencionalidad propuesta por un grupo social.

En este sentido, el discurso, como afirma Van Dijk (1997: 21), "no se limita a la acción verbal, sino que involucra significado, interpretación y comprensión, lo cual significa que el acceso preferente al discurso público o el control sobre sus propiedades también puede afectar al pensamiento de los demás”. Esto quiere decir, que los agentes sociales con mayor poder y control sobre las distintas formas de institucionalidad social, tienen la facultad, los mecanismos y los recursos para establecer formas de pensamiento asociadas a sus intereses, lo que trae como efecto el cambio de actitudes y opiniones, en la medida que la apropiación del discurso de la prensa guarde relación con el imaginario social dispuesto por un grupo social.

Por lo mismo, en el actuar de la prensa se observa que al producir un conjunto de discursos como resultado de las coberturas respectivas de los acontecimientos relacionados con un conflicto social, los cuales son seleccionados sobre la base de la noción de actualidad y prominencia, características intrínsecas en el periodismo; el dispositivo mediático hace uso de elementos sígnicos del pasado para establecer una explicación de los fenómenos acontecidos en el presente con la finalidad de reproducir una significación socioimaginaria deseada en el espacio de la memoria colectiva de las audiencias.

Por lo demás, el discurso de la prensa como mecanismo de interacción y lucha de significados, produce un sentido que se acoge al sistema simbólico del enunciador y articula un relato verosímil que contempla los elementos de significación utilizados para representar su propia visión del mundo legitimada por la institución y por medio de la acción que le adjudique una coherencia compartida, ya que el discurso no tiene una coherencia propia sino que posee coherencia a partir de la asignación que le dan los propios usuarios del lenguaje y, como lo señala Joseph Courtés (1995), el contenido de un discurso es interpretable únicamente bajo las reglas impuestas en el juego que se establece entre el enunciador y el enunciatario.

\section{Algunas precisiones sobre los imaginarios sociales}

Pues bien, al considerar el gran aporte teórico que nos ha heredado el pensamiento de Cornelius Castoriadis (2007, 2004 y 2001) -complementado con los aportes decisivos de autores contemporáneos como Manuel Antonio Baeza (2008 y 2003) y Juan Luis Pintos (1994 y 2005)- nos planteamos la necesidad de elaborar una descripción de la noción de imaginarios sociales y, a su vez, destacar la importancia de la práctica social discursiva en la construcción de imaginarios sociales en nuestras sociedades.

Es por ello que quisiéramos comenzar diciendo que para precisar lo que entenderemos por imaginarios sociales, nos apoyamos en la idea pro- 
puesta por Cornelius Castoriadis respecto al término de imaginario:

"Hablamos de imaginario cuando queremos hablar de algo 'inventado' -ya se trate de un invento 'absoluto' ('una historia imaginada de cabo a rabo'), o de un deslizamiento, de un desplazamiento de sentido, en el que unos símbolos ya disponibles están investidos con otras significaciones que las suyas 'normales' o canónicas [...] En los dos casos, se da por supuesto que lo imaginario se separa de lo real, ya sea que pretenda ponerse en su lugar (una mentira) o que no lo pretenda (una novela)" (Castoriadis, 2007: 204).

En este sentido, la propuesta inicial de Castoriadis acerca del concepto de imaginario se centra en la capacidad que posee lo imaginario para expresarse a través de lo simbólico, para ser visible en el entramado social y, por ende, se establece que la articulación entre significados y significantes permite una movilidad en el lenguaje y la construcción de significaciones, o sea nos faculta como actores sociales para evocar una imagen -y más que simples imágenes- por medio de lo enunciado y llenar de sentido lo construido socialmente.

Por tanto, para Castoriadis (Ibid: 536) "la significación es aquí la coparticipación de un término y de aquél al que ese término remite, poco a poco, directa o indirectamente. La significación es un haz de remisiones a partir y alrededor de un término”. No obstante, obviar la existencia de un referente(s) de la palabra, subordina la palabra para ser usada -únicamente- en el sentido que le corresponde de manera directa. Así entonces, Castoriadis (Ibid: 540-541) afirma que:
"una palabra, aun cuando se la utilice en su pretendido «sentido pro- pio», o con su «significación cardinal», es utilizada en un sentido trópico. No existe el ‘sentido propio'; lo único que existe -pero siem- pre, e ineliminablemente, ya sea en las metáforas como en las alego- rías más sutiles o más disparatadas- es la referencia identitaria, pun- to de una red de referencias identitarias, aprehendido él mismo en el magma de las significaciones y referido al magma de lo que es”.

Incluso, es factible asumir que en el caso puntual de la producción discursiva dentro de las sociedades occidentales, el imaginario social mediante lo simbólico permite la construcción social de la realidad, establece una realidad determinada y genera pertenencia. Por lo tanto, el discurso de la prensa al ser entendido como un articulador de significaciones, tiene la función dentro de la lógica societal, por una parte, de expresar la visión del mundo que los grupos de poder construyen y, por otra, ser la esfera concreta donde se lleva a cabo una construcción de la realidad social configurada sobre la base de las acciones de un grupo social movilizado y de los elementos significativos presentes en el discurso de los agentes políticos y económicos dominantes en la actualidad.

Vale la pena seguir a Castoriadis, quien nos ayuda a precisar nuestra 
sucinta reflexión acerca de la relación entre el imaginario social y lo simbólico:

“Las relaciones profundas entre lo simbólico y lo imaginario aparecen enseguida si se reflexiona en este hecho; lo imaginario [social] debe utilizar lo simbólico, no sólo para «expresarse», lo cual es evidente, sino para «existir», para pasar de lo virtual a cualquier otra cosa más” (Ibid: 204).

Sin embargo, agrega Castoriadis:

"La influencia decisiva de lo imaginario [social] sobre lo simbólico puede ser comprendido a partir de esta consideración: el simbolismo supone la capacidad de poner entre dos términos un vínculo permanente de manera que uno 'represente' al otro. Pero no es más que en las etapas muy avanzadas del pensamiento racional lúcido en las que estos tres elementos (el significante, el significado y su vínculo sui generis) se mantienen como simultáneamente unidos y distintos, en una relación a la vez firme y flexible” (Ibid: 205).

Al hilo de las ideas expresadas es posible evidenciar que los imaginarios sociales corresponden a constructos de sentido acerca de algo o alguien, singular o plural, individual o colectivo, público o privado, que han sido construidos socialmente a través de los dispositivos de poder existentes dentro del tejido social y que poseen un reconocimiento y legitimidad dentro del conjunto de la sociedad. Me refiero concretamente a la comprensión de los imaginarios sociales como constructos de sentido que poseen legitimidad para los usuarios del lenguaje y los integrantes de una sociedad, producto de un largo proceso de socialización amparado en la acción de instituir una significación compartida por aquéllos. En otras palabras:

"Los imaginarios sociales, al decir que son esquemas sui generis de construcción/inteligibilidad simbolizada de la realidad, se presentan frente a nosotros como amplios constructos simbólicos socializados, compartidos mediante la comunicación intersubjetiva de las personas, por lo tanto autolegitimados, alimentando así la pretensión de alcanzar la categoría de verdad incuestionable para quienes así lo han internalizado” (Baeza, 2003: 51).

En complemento con lo anterior, Juan Luis Pintos (2005) entiende a los imaginarios sociales como esquemas que han sido socialmente construidos con la finalidad de permitir a las personas que constituyen una sociedad la percepción, explicación e intervención de la realidad. Esto lo explica J. L Pintos (Ibid: 43) de la siguiente manera:

1. Esquemas socialmente construidos: significa que su entidad posee un elevado grado de abstracción semejante a las referencias temporales que implican una determinada constancia en la 
secuencialidad, priorización y jerarquización de nuestras percepciones a través del código relevancia/opacidad socialmente diferenciado.

2. Que nos permiten percibir, explicar e intervenir: las operaciones complejas a las que se refieren estos verbos son posibles para nosotros porque disponemos de un "mundo a nuestro alcance" y una "distribución diferenciada del conocimiento", que posibilita unas referencias semejantes de percepción (espaciales, temporales, geográficas, históricas, culturales, religiosas, etc.), de explicación (marcos lógicos, emocionales, sentimentales, biográficos, etc.) y de intervención (estrategias, programas, políticas, tácticas, aprendizajes, etc.).

3. Lo que en cada sistema social diferenciado se tenga por realidad: no hay una única realidad, que se identificaría necesariamente con una verdad única. Nuestras sociedades contemporáneas no se configuran bajo el modelo de sistemas únicos y de referencias absolutas, sino que están sometidas a procesos evolutivos de progresivas diferenciaciones sistémicas.

Frente a este escenario conceptual articulado sobre la base de los planteamientos de C. Castoriadis (2007, 2004 y 2001), J. L. Pintos (1994 y 2005) y M. A. Baeza (2008 y 2003), sostenemos que el discurso de la prensa, por una parte, es una construcción comunicativa simbólica ${ }^{2}$ que materializa el imaginario social y, por otra, como dispositivo y acción comunicativa que se gesta en el seno de la sociedad a partir de las interacciones entre personas y colectivos, es -a su vez- el espacio donde se puede construir y cristalizar, modificar o reemplazar los imaginarios sociales acuñados mediante las significaciones socialmente compartidas y las dinámicas ideológicas instauradas por los grupos de poder. Así entonces:

"Una vez creadas, tanto las significaciones imaginarias sociales como las instituciones se cristalizan o se solidifican, y es lo que llamo el imaginario social instituido. Este último asegura la continuidad de la sociedad, la reproducción y la repetición de las mismas formas, que de ahora en más regulan la vida de los hombres y permanecen allí hasta que un cambio histórico lento o una nueva creación masiva venga a modificarlas o a reemplazarlas radicalmente por otras formas" (Castoriadis, 2001: 96).

Para concluir quisiéramos volver a Castoriadis para afirmar que la historia del hombre es -en sí misma- la historia del imaginario humano, puesto que no existe sociedad fuera de lo que hombre ha construido, es decir fuera de toda empresa imaginaria tanto radical como social y, por ende, "resulta absolutamente natural llamar a esta facultad de innovación radical, de creación y de formación, imaginario e imaginación. El lenguaje, las costumbres, las normas, las técnicas no pueden ser explicados por factores exteriores a las colectividades humanas" (Ibid: 94). 


\section{Aspectos metodológicos del estudio}

En el plano epistemológico, entendemos que la realidad social es construida por los individuos mediante la acción intersubjetiva y que, a su vez, comparten significados en común respecto a dicha realidad social construida. Por lo tanto, es posible conocer un fenómeno socio-comunicacional desde una perspectiva cualitativa compatible con los fundamentos teóricos que sustentan el marco comprensivo y descriptivo de nuestro estudio, donde, además, se asume como parte del trabajo de análisis de un investigador la intención de objetivar un fenómeno constituyente de una realidad social.

Así entonces, para los fines de nuestra investigación se comparte lo enunciado por Manuel Antonio Baeza (2008: 45) respecto a la objetivación entendida "-en un sentido simple-como un compromiso entre lo materialmente dado y lo subjetivamente entendido como dado; [y] -en un sentido complejo- como un esfuerzo intelectual riguroso para convertir en evidencias aspectos visibles y no visibles de la realidad" [...] realidad que -desde nuestro punto de vista- se hace presente en el discurso de la prensa, es decir, la prensa es un dispositivo que materializa el imaginario social en el entramado de relaciones sociales.

\section{Unidad de información y corpus de análisis}

Ahora bien, respecto a la unidad de información utilizada en el marco de la presente investigación, se reconoce que el diario El Mercurio de Chile $^{3}$ establece una red de relaciones de poder marcadas por el grado de influencia en el quehacer político y económico del país donde son distribuidos y adquiridos sus ejemplares por las audiencias del territorio nacional. Asimismo, El Mercurio de Chile juega un papel central en la configuración de la opinión pública producto del reconocimiento y legitimidad que los actores más influyentes de la política y la economía le han otorgado. En términos más precisos, el diario El Mercurio fue seleccionado según los siguientes criterios:

1. Por la cobertura nacional que alcanza.

2. Por la importancia que tiene en la configuración de la opinión pública a nivel nacional.

3. Por los niveles de lectoría a nivel nacional.

4. Por la antigüedad que posee este diario en América Latina: El Mercurio de Santiago de Chile, su primer ejemplar se publicó el 1 de junio de 1900 .

5. Por ser una de las empresas periodísticas fundadoras en 1991 del

“Grupo de Diarios América” (GDA). Consorcio mediático que en la 
actualidad reúne a 11 empresas periodísticas (específicamente del sector de la prensa escrita) que poseen una gran influencia política y económica en sus respectivos mercados nacionales.

Por su parte, el material analizado está conformado por un corpus de textos que corresponden a 10 editoriales publicadas por el diario El Mercurio de Chile, entre diciembre de 2001 y enero de 2002. Por consiguiente, el corpus fue seleccionado según los siguientes criterios:

\section{Tabla $\mathbf{N}^{\circ} 1$. Criterios de selección del corpus textual.}

\begin{tabular}{|l|l|}
\hline Categoría & \multicolumn{1}{|c|}{ Descripción } \\
\hline Tipo de discurso & Todo discurso de la prensa que corresponda a una editorial. \\
\hline $\begin{array}{l}\text { Tópico o temática } \\
\text { central }\end{array}$ & $\begin{array}{l}\text { Todo discurso editorial donde se hace referencia a las acciones } \\
\text { colectivas de protesta y a la crisis argentina de 2001. }\end{array}$ \\
\hline $\begin{array}{l}\text { Tipo de medio de } \\
\text { comunicación }\end{array}$ & $\begin{array}{l}\text { Todo discurso editorial producido por la prensa escrita donde se hace } \\
\text { referencia a las acciones colectivas de protesta y a la crisis argentina } \\
\text { de 2001. }\end{array}$ \\
\hline $\begin{array}{l}\text { Identificación de la } \\
\text { prensa escrita }\end{array}$ & $\begin{array}{l}\text { Todo discurso editorial producido por el diario El Mercurio de Chile } \\
\text { donde se hace referencia a las acciones colectivas de protesta y a la } \\
\text { crisis argentina de 2001. }\end{array}$ \\
\hline Temporalidad & $\begin{array}{l}\text { Todo discurso editorial del diario El Mercurio de Chile publicado } \\
\text { entre diciembre de 2001 y enero de 2002, donde se hace referencia a } \\
\text { las acciones colectivas de protesta y a la crisis argentina de 2001. }\end{array}$ \\
\hline
\end{tabular}

Fuente: Elaboración propia.

A continuación, se presenta el detalle del corpus analizado.

Tabla $N^{\circ} 2$. Identificación del corpus textual.

\begin{tabular}{|l|l|l|l|}
\hline$N^{\circ}$ & $\begin{array}{l}\text { Diario } \\
\text { (Prensa) }\end{array}$ & Titulares - Editoriales & Fecha de Publicación \\
\hline 1 & El Mercurio & Crisis argentina (I) & 9 de Diciembre de 2001 \\
\hline 2 & E1 Mercurio & Incertidumbre en Argentina (I) & 15 de Diciembre de 2001 \\
\hline 3 & El Mercurio & Crisis argentina (II) & 16 de Diciembre de 2001 \\
\hline 4 & El Mercurio & Incertidumbre en Argentina (II) & 22 de diciembre de 2001 \\
\hline 5 & E1 Mercurio & Frutos de la tercera vía & 26 de diciembre de 2001 \\
\hline 6 & E1 Mercurio & Presidente provisorio en Argentina & 30 de diciembre de 2001 \\
\hline 7 & El Mercurio & Efectos de la crisis trasandina & 2 de enero de 2002 \\
\hline 8 & El Mercurio & Crisis en Argentina & 5 de enero de 2002 \\
\hline 9 & E1 Mercurio & $\begin{array}{l}\text { La economía de mercado no es } \\
\text { sólo mercado }\end{array}$ & 6 de enero de 2002 \\
\hline 10 & E1 Mercurio & Argentina & 10 de enero de 2002 \\
\hline
\end{tabular}

Fuente: Elaboración propia. 


\section{Descripción del método de análisis}

Pues bien, con la finalidad de dar cumplimiento a los objetivos planteados en el presente trabajo, se utiliza un modelo de análisis del discurso periodístico diseñado e implementado en instancias investigativas elaboradas por académicos del Grupo de Investigación en Comunicación y Saberes Críticos de la Universidad de La Frontera, a saber: 1) proyecto FONDECYT $\left.\mathrm{N}^{\circ} 1100264,2\right)$ Proyecto FONDECYT Nº 1120904 y 3) Proyecto DIUFRO $\mathrm{N}^{\circ}$ DI120060. En esta medida, nuestro modelo de análisis del discurso nos permitirá, por una parte, identificar los tópicos, contextos, figuras, roles y valores temáticos; y, por otra, describir las posiciones de poder, los modos de objetivación y los elementos de significación que configuran los imaginarios sociales de la acción colectiva de protesta y la crisis argentina de 2001 en el discurso editorial del diario El Mercurio de Chile. En síntesis, el modelo de análisis del discurso que utilizamos en este trabajo nos permite estudiar el discurso de la prensa producido por el diario El Mercurio de Chile con la intención de describir el imaginario social construido por este dispositivo de poder vinculado al Consorcio Latinoamericano "Grupo de Diarios América” (GDA).

A continuación, procedemos a la descripción de los componentes del modelo de análisis del discurso utilizado:

\section{Tabla $\mathbf{N}^{\circ} 3$. Modelo de análisis del discurso.}

\begin{tabular}{|c|c|c|}
\hline Tópico(s) & Figuras / Recorridos & Valores Temáticos \\
\hline $\begin{array}{l}\text { Es el tema que engloba el sentido } \\
\text { de un discurso o parte de él y que, } \\
\text { a su vez, posee una lógica interna } \\
\text { en relación al contexto. }\end{array}$ & $\begin{array}{l}\text { Consiste en identificar las } \\
\text { distintas figuras (actores, } \\
\text { instituciones, tiempo(s), } \\
\text { lugar(es), que aparecen en el } \\
\text { discurso y el papel que se les } \\
\text { asigna a cada uno en el relato. }\end{array}$ & $\begin{array}{l}\text { Es el sentido que se } \\
\text { construye a partir de las } \\
\text { relaciones entre las figuras } \\
\text { y sus recorridos } \\
\text { figurativos. Por lo tanto, las } \\
\text { figuras tienen un valor a } \\
\text { partir de su relación con } \\
\text { otras figuras. }\end{array}$ \\
\hline Posición de Poder & Modos de objetivación & Contexto(s) \\
\hline $\begin{array}{l}\text { Corresponde a la identificación de } \\
\text { la posición del hablante (en el } \\
\text { discurso) en relación con un } \\
\text { sujeto/institución/objeto existente } \\
\text { en la dinámica de la realidad } \\
\text { social. }\end{array}$ & 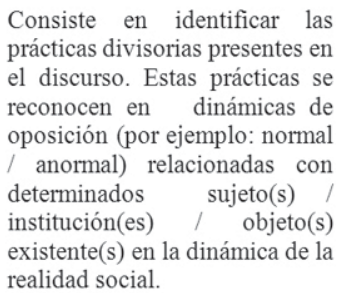 & $\begin{array}{l}\text { Corresponde a la acción de } \\
\text { identificar el contexto(s) en } \\
\text { el que se desarrollan los } \\
\text { elementos constituyentes } \\
\text { del discurso y que } \\
\text { determinan la adscripción } \\
\text { de un significado en } \\
\text { relación a una situación o } \\
\text { hecho. }\end{array}$ \\
\hline
\end{tabular}

Fuente: Elaboración propia. 


\section{Resultados del análisis}

Es necesario establecer que producto del análisis realizado al corpus constituido por 10 editoriales del diario chileno El Mercurio, se observan cuatro ejes discursivos desde donde el discurso de la prensa articula la construcción socioimaginaria en torno a la acción colectiva de protesta y la crisis argentina de 2001, tal como se observa en la figura 1:

Fig 1. Ejes discursivos presentes en el diario El Mercurio de Chile.

\section{Acción colectiva de protesta}

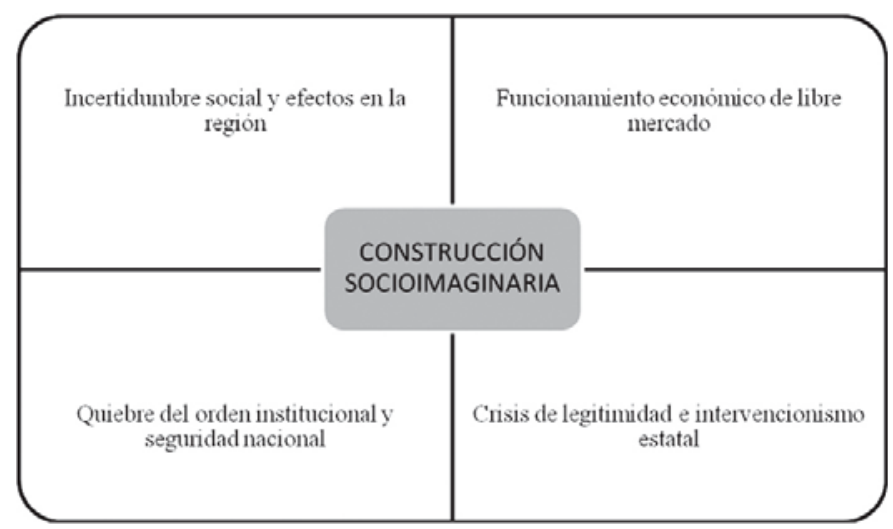

Crisis Argentina de 2001

Fuente: Elaboración propia.

\section{En torno al imaginario social de la acción colectiva de protesta}

Lo primero que debemos destacar es que mediante el análisis del corpus se logra establecer que el discurso del diario El Mercurio presenta argumentos que estructuran una evaluación negativa acerca de la violencia social que se observa en las calles de Buenos Aires y de otras ciudades de Argentina. En este sentido, el discurso del diario El Mercurio desarrolla una disposición crítica acerca de las lecciones que debemos obtener de las acciones colectivas de protesta ocurridas en Argentina en la medida que predispone un juicio rotundo en torno a los desbordes sociales y sus efectos en el desarrollo democrático de los países de América Latina. Incluso, este sistema de discursos producidos por el diario El Mercurio instituye un tipo de advertencia sobre las consecuencias económicos y sociales que acarrea 
el desorden público, la inseguridad y, por ende, la falta de gobernabilidad en lo que respecta a un país como es el caso de Argentina y los efectos que puede traer a los demás países de la región latinoamericana.

Es así como el discurso del diario El Mercurio construye un imaginario social de la acción colectiva de protesta a partir de la significación negativa que posee un fenómeno interno de protesta social que se gesta como respuesta al proceso dicotómico de exclusión/inclusión respecto al modelo económico de libre mercado y que no debe expandirse por el continente puesto que atentaría contra la necesidad de salvaguardar el desarrollo económico y la democracia existente en Argentina como en América Latina. Además, el imaginario social de la acción colectiva de protesta se ha configurado en torno a la centralidad que adquiere en el discurso del diario El Mercurio las referencias a los piquetes en las rutas, el desorden público, la violencia desmedida, los cacerolazos y el vandalismo ejercido por parte de los miembros indignados de las capas bajas y medias de la sociedad argentina, quienes responden con violencia frente a la corrupción del sistema político, irresponsabilidad en el manejo de la crisis económica y ausencia de soluciones a corto o mediano plazo por parte del gobierno de Fernando de la Rúa para enfrentar la crisis, tal como se ve en la figura 2.

\section{Fig 2. Estructura del imaginario social de la acción colectiva de protesta}

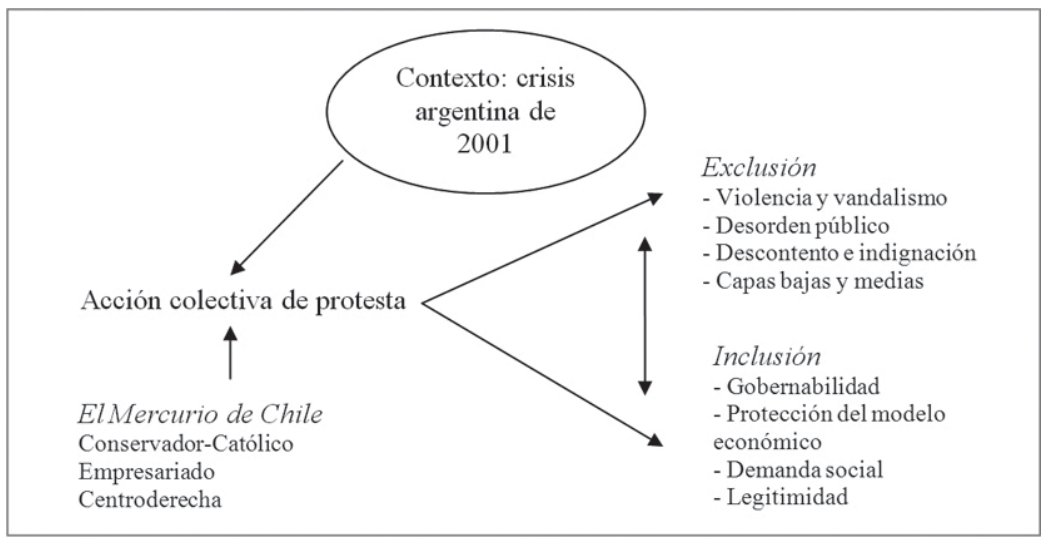

Vale la pena destacar que el imaginario social de la acción colectiva de protesta se instaura a partir de la significación negativa para la gobernabilidad de un país, lo que -en consecuencia- permite que se convierta en un elemento nuclear a partir del cual el diario El Mercurio organiza discursivamente la defensa y protección del imaginario social de la economía de libre mercado. En este sentido, la noción de acción colectiva de protesta adquiere una significación de amenaza para el modelo económico 
neoliberal en la medida que representa el retorno del fantasma de la década perdida, y si consideramos la propuesta del diario El Mercurio en torno a la necesidad de restablecer el orden público a la brevedad posible, entonces estamos en presencia de una exigencia o condición impuesta desde la práctica discursiva para que el gobierno argentino estabilice su situación económica y social pero con la clara intención de proteger el modelo económico de libre mercado que ha sido cuestionado producto de los niveles de exclusión a los que se ha sometido a la población argentina.

El punto que nos interesa remarcar es precisamente que el discurso del diario El Mercurio en torno al imaginario de la acción colectiva de protesta se sustenta sobre la base de las figuras discursivas de la clase media, los pobres y desempleados (piqueteros), vistos como los representantes del sufrimiento producto de la crisis económica que afecta a la Argentina y que se explica a partir de los problemas y errores cometidos en la implementación del modelo de desarrollo económico de libre mercado que generó una grave situación con altos costos sociales para el pueblo argentino. Y que, por lo demás, es la causa principal de las acciones colectivas de protesta gestadas en las calles de diversas ciudades. En esta medida, el diario El Mercurio utiliza la noción de pueblo argentino para enmarcar la indignación popular contra el sistema político y la presión social que ejercen sobre el sistema económico estas capas cohesionadas a partir de los eventos económicos que los apremian.

Ahora bien, frente a este panorama de crisis económica que se manifiesta en las calles a través de la acción colectiva de protesta de los miembros de las clases bajas y medias, quisiéramos profundizar un poco más acerca del imaginario social del modelo económico de libre mercado que el diario El Mercurio cristaliza a partir de una doble significación en tanto negativa de la violencia y las demandas de los ciudadanos que protestan en las calles, como positiva a partir de un ideal como es la estabilidad económica, la generación de empleo (sin precisar el tipo o calidad de este último) y la inclusión de la mayoría de los indignados a la senda del desarrollo. En este sentido, la lógica argumental del diario El Mercurio se sustenta en la enunciación de un tipo de advertencia pública y juicio negativo acerca de la forma como -específicamente en el caso de Argentina- se ha implementado de forma incorrecta y con serias deficiencias el modelo económico de libre mercado, por tanto la viabilidad del modelo económico sustentado en la libertad y autorregulación de los mercados no debe ser cuestionada a partir de la crisis que se sucede en Argentina, en la medida que en este caso el modelo económico se ve afectado por una intervención del Estado mediante regulaciones rígidas, desmesurado gasto público y excesiva burocracia. Es decir, se instala un constructo de sentido que cristaliza una defensa y protección del imaginario social neoliberal que fomenta el desarrollo de las instituciones y prácticas asociadas al modelo económico de libre mercado como las únicas entidades y estrategias capaces de permitir al Estado Argentino retomar los niveles de crecimiento económico, estabilización de los indicadores de desempleo y apertura de sus mercados a los capitales extranjeros, que -desde la lógica del corpus analizado- corresponderían a 
factores que se ven dañados por la falta de gobernabilidad y permisividad por parte del Estado respecto a la prolongada duración e intensidad de las protestas sociales en el país.

Cabe acá mencionar que, incluso, en el discurso del diario El Mercurio se advierte una preocupación por la capacidad de las autoridades argentinas para procurar un consenso necesario que permita restablecer el orden público, la paz social y el funcionamiento de las instituciones sobre la base de un plan económica de emergencia que logre disminuir los actos de violencia ejecutados por diversos actores sociales. No obstante, si no se cumple con lo antes mencionado, se condiciona el apoyo y la cooperación de los países del mundo, lo que incluye a Chile. Acá podemos apreciar como el diario El Mercurio construye un imaginario social de la acción colectiva de protesta y del modelo económico de libre mercado a partir de la configuración de un conjunto significativo de referencias en torno al estancamiento del desarrollo económico de una país producto de la aplicación de políticas estatistas y proteccionistas, por tanto este tipo de lógica estatal de carácter intervencionista y corrupta atenta contra la solidez institucional, el emprendimiento empresarial y el libre flujo de capitales e inversiones a nivel global. Es decir, si esta es la modalidad de funcionamiento del Estado argentino entonces es factible identificar las razones de la crisis y determinar a los responsables de los malos resultados obtenidos por la errada implementación del modelo de libre mercado en este país.

\section{En torno al imaginario social de la crisis argentina de 2001}

Respecto al imaginario social de la crisis argentina de 2001, cabe explicitar un aspecto esencial: el imaginario social de la crisis argentina corresponde a una concepción socioimaginaria de tipo político que funciona, por una parte, en términos de respuesta medular y plausible acerca del origen y sentido de las acciones colectivas de protesta; y, por otra, como ideación de un sistema político en crisis producto de los niveles de corrupción y desconfianza en sus autoridades. Con el propósito de confirmar lo enunciado, podemos evidenciar como el imaginario social de la crisis argentina de 2001 adquiere un carácter de realidad social plausible mediante una evaluación de carácter negativa por parte del discurso del diario El Mercurio sobre la administración y gestión de la crisis (en ese momento histórico) del Presidente Fernando de la Rúa. En este sentido, esta realidad social plausible centrada en la figura de un Presidente de la República se legitima en la medida que el discurso del diario El Mercurio sustenta esta materialidad sobre la base de un conjunto de juicios axiológicos en torno a la ausencia de liderazgo, la desconfianza de la población en la gestión presidencial, la fragmentación de posiciones políticas al interior de su gobierno y la falta de apoyo por parte de los partidos políticos oficialistas como de oposición. Consecuencia de aquello, el imaginario social de la crisis argentina de 2001 corresponde a una red de relaciones de sentido 
construida sobre la base de la incertidumbre, la desconfianza, la violencia y la ingobernabilidad.

Que más ilustrativo de lo anterior es cuando el discurso del diario El Mercurio, por una parte, cristaliza el imaginario social de la crisis argentina de 2001 a partir de las referencias constantes a la incertidumbre, la desconfianza y la violencia en la medida que responden a elementos nucleares en torno a los cuales se sustenta una respuesta al enigma de la estabilidad económico y el respeto a la institucionalidad republicana de Argentina, y por otra, configura el sentido de la crisis argentina de 2001 a partir de la dualidad gobernabilidad/ingobernabilidad, específicamente, cuando se elaboran argumentos en torno a las posibles consecuencias económicas que puede provocar esta situación de crisis en las relaciones comerciales entre los países latinoamericanos y, por supuesto, los efectos sobre el deterioro que se observa en las dinámicas de seguridad interna que presenta Argentina y que preocupan a los países vecinos, tal como se ve en la figura 3.

\section{Fig. 3 Estructura del imaginario social de la crisis argentina de 2001}

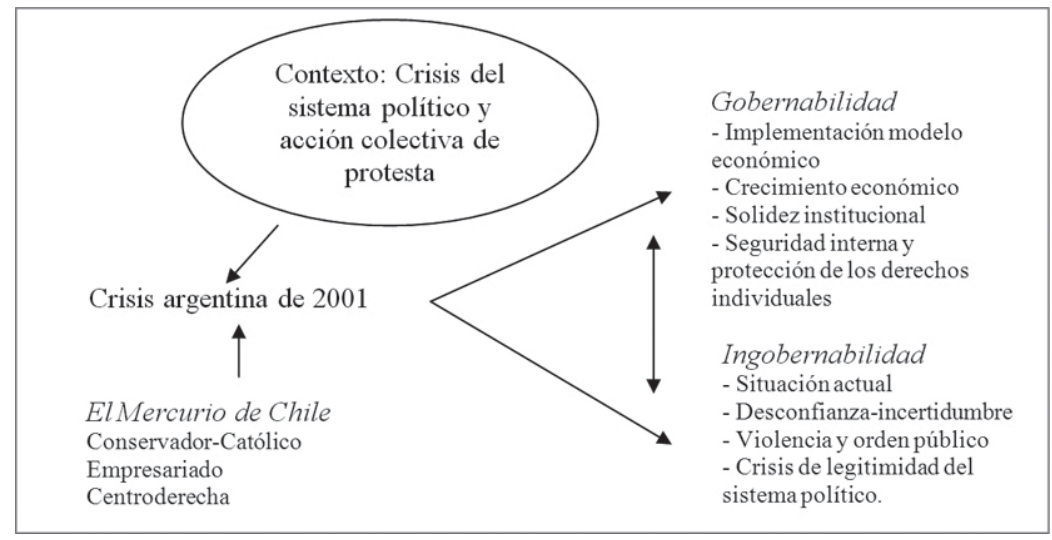

De igual forma, se establece una clara posición de poder en el discurso editorial del diario El Mercurio de Chile cuando se crítica a los diversos actores y sectores políticos argentinos (objetivados en las figuras de Fernando de la Rúa, Carlos Menem, Justicialismo, entre otras), quienes serían identificados como los responsables de la situación de crisis actual y los causantes de la inestabilidad social que afecta a dicho país y que puede, a su vez, desestabilizar los procesos sociopolíticos y socioeconómicos de países colindantes. En otras palabras, las figuras discursivas adscritas al sistema político argentino son desvalorizadas por la prensa en términos de su falta de legitimidad, capacidad de liderazgo y ausencia de toda autoridad necesaria para el restablecimiento del orden institucional y la seguridad interna. Incluso, el discurso editorial dispone de una posición de poder 
que proyecta cambios fundamentales en los cargos políticos de mayor jerarquía dentro del Poder Ejecutivo de Argentina y advierte acerca de los desafíos que debe enfrentar las nuevas autoridades producto del conflicto en las calles, el estallido social, la inseguridad y el caos gestado por la movilización de fuerzas populares empoderadas y articuladas sobre la base de demandas comunes a varias clases sociales (desde los piqueteros-pobres-marginados a los funcionarios público-empobrecidos-desempleados). Es decir, lo anterior lo podemos precisar en la medida que el discurso editorial de la prensa en Chile enfatiza los desafíos inmediatos que debe responder el mandatario provisional de la Nación Argentina, Adolfo Rodríguez Saá: 1) restablecer el orden en el país, 2) aplicar medidas económicas de emergencia para responder a los compromisos financieros del Estado, y 3) concitar los consensos necesarios tanto al interior del país como en el escenario internacional para lograr una base de apoyo a las reformas exigidas por los actores financieros internacionales/supranacionales (Fondo Monetario Internacional y Banco Mundial).

De este modo y como ya hizo referencia anteriormente, en el caso del diario El Mercurio de Chile se identifica una construcción socioimaginaria de la crisis argentina asociada a la idea de ingobernabilidad y ausencia de liderazgo político cuando este discurso de prensa, por una parte, elabora referencias directas al rol que deben cumplir el Congreso y los parlamentarios argentinos frente al problema económico y la crisis política que vive en el país; y, por otra, argumenta que la violencia desmedida que se observa en distintas ciudades argentinas es producto de la incapacidad de la autoridad máxima del país para intervenir en el descontrol de las fuerzas policiales y los ciudadanos que se enfrentan día a día en las calles. En sentido, el discurso del diario El Mercurio de Chile utiliza tiene la capacidad de generar una red de relaciones de sentido que remiten a la ausencia de una gobernabilidad como elemento nuclear que pone en riesgo los desafíos del Estado Argentino transitorio. En consecuencia, este imaginario social de la crisis argentina se instala con fuerza en el discurso de prensa del diario El Mercurio de Chile en la medida que la significación de la ingobernabilidad conlleva a poner un manto de duda sobre la legitimidad del sistema económico de libre mercado en América Latina. Por tanto, este discurso de prensa construye argumentos que critican directamente a los sectores políticos, las elites y el pueblo argentino, quienes serían responsables de la profundización de la crisis actual y, en términos políticos se logra cristalizar el juicio de una falta de visión y claridad para resolver el problema a partir del cumplimiento de las exigencias dispuestas por los países latinoamericanos pero en especial por los organismos financieros internacionales como condición sine qua non para un rescate o entrega de ayuda.

\section{Conclusiones}

La crisis argentina de 2001 y las acciones colectivas de protesta que se generaron en el marco de esta crisis, corresponden a eventos relevantes de la política contemporánea que marcaron el comienzo del presente siglo, 
siendo de suma relevancia para el campo de los estudios en ciencias sociales las acciones colectivas de protestas que de manera inevitable lograron atraer a los medios de comunicación, los cuales realizaron coberturas periodísticas y construyeron un sistema de discursos donde se cristalizan los imaginarios sociales. En suma, los imaginarios sociales que se disponen en el conjunto de discursos producidos por la prensa en torno a las acciones colectivas de protesta ocurridas en el marco de la crisis argentina de 2001, han sido construidos socialmente y reproducidos a través de los medios de comunicación que son definidos como dispositivos de poder simbólico capaces de acuñar significaciones imaginarios sociales dentro del tejido social. Por lo tanto, si los medios de comunicación son dispositivos de poder simbólico que articulan esquemas interpretativos acerca de los distintos acontecimientos y como tales son capaces de construir socialmente una realidad, entonces no cabe duda alguna que los medios de comunicación en su condición de productores y reproductores de imaginarios sociales poseen una relevancia en el espacio público. Por tanto, todo discurso es el reflejo de la acción y expresión de lo público a través del ejercicio del lenguaje, por ende en el actual detrimento (se niega la condición de eliminación) que afecta al lugar-espacio donde las personas se reúnen para intercambiar ideas, opiniones e incluso debatir acerca de los temas que afectan a la totalidad de los ciudadanos, los medios de comunicación han adquirido la autoridad y legitimidad necesaria para convertirse en un espacio formal y público donde las audiencias se apropian de los mensajes-acontecimientos tanto relevantes como superfluos del acontecer diario.

Así entonces, desde nuestra perspectiva los mundos posibles y la red de relaciones de sentido que configuran los medios de comunicación en términos de aparatos ideológicos "ofrecen un modelo del mundo reconocible en el entorno o tácticamente posible; sugieren a los actores comportamientos factibles y aceptados; y describen situaciones que suelen ser las más probables” (Martín Serrano, 1986: 44). A fin de cuentas, la condición ideológica de los medios de comunicación determina la configuración de un objeto duplicado in absentia del objeto real y se establece una mímesis sobre la base de la presencia (simulación) de algunas propiedades del objeto representado. A partir de lo descrito, se puede observar que los medios de comunicación elaboran discursos donde los significados que se adscriben a los acontecimientos del presente, siempre están alineados en la medida que sean favorables a los objetivos propuestos por el enunciador. 
Polis, Revista Latinoamericana, Volumen 12, No 34, 2013

\section{Notas}

${ }^{1}$ Este trabajo forma parte de los siguientes proyectos de investigación: 1) Proyecto FONDECYT N¹100264, financiado por el Fondo Nacional de Desarrollo Científico y Tecnológico de Chile; y 2) Proyecto DIUFRO N DI120060, financiado por la Dirección de Investigación de la Universidad de La Frontera (Temuco, Chile).

${ }^{2}$ Desde nuestra visión teórica, se asume la importancia del discurso como dispositivo que materializa el imaginario social en el entramado de relaciones sociales y, además, "si consideramos el discurso "como el fluir del conocimiento -y de todo el conocimiento societal acumulado- a lo largo de toda la historia”, [entonces se entiende la relevancia del término fluir en el sentido de la acción que] determina los hechos individuales o colectivos, así como la acción formativa que moldea la sociedad y que, de este modo, ejerce el poder. [Por consiguiente], los discursos pueden comprenderse como realidades sui generis (Jäger, 2003: $63)$.

${ }^{3}$ Véase diario El Mercurio de Chile http://www.elmercurio.cl 


\section{Bibliografía}

Auyero, Javier. (2004), “¿Por qué grita esta gente? Los medios y los significados de la protesta popular en la Argentina de hoy”, en América Latina Hoy. Abril. N 036, Universidad de Salamanca, pp. 161-185.

Baeza, Manuel Antonio. (2008), Mundo real, mundo imaginario social. Teoría y práctica de sociología profunda, RIL Editores, Santiago de Chile.

Idem (2003), Imaginarios sociales. Apuntes para la discusión teórica y metodológica, Editorial Universidad de Concepción, Chile.

Battistini R, Osvaldo. (2007), “Luchas sociales en crisis y estabilidad”, en Villanueva, Ernesto y Massetti, Astor (Comp). Movimientos sociales y acción colectiva en la Argentina de hoy, Prometeo, Buenos Aires.

Castoriadis, Cornelius. (2007), La institución imaginaria de la sociedad, Tusquets Editores, Buenos Aires.

Idem (2004), Sujeto y verdad en el mundo histórico-social, Fondo de Cultura Económica, Buenos Aires.

Idem (2001), Figuras de lo pensable. Las encrucijadas del laberinto VI, Fondo de Cultura Económica, México.

Courtés, Joseph. (1995), Análisis semiótico del discurso. Del enunciado a la enunciación, Editorial Gredos, Madrid.

Favaro, Orietta, Iuorno, Graciela y Cao, Horacio. (2006), "Política y protesta social en las provincias argentinas”, en Caetano, Gerardo. Sujetos sociales y nuevas formas de protesta en la historia reciente de América Latina, CLACSO (Consejo Latinoamericano de Ciencias Sociales), Buenos Aires.

Goicovic, Igor. (2000), "Del control social a la política social. La conflictiva relación entre los jóvenes populares y el Estado en la historia de Chile”, en Revista Última Década, N 12, pp. 103-123.

Habermas, Jurgen. (1999), Problemas de legitimación en el capitalismo tardío, Cátedra, Madrid.

Iazzetta, Osvaldo. (2007), Democracia en busca de Estado. Ensayos sobre América Latina, Homo Sapiens Ediciones, Buenos Aires.

Jäger, Siegfried. (2003), Discurso y conocimiento: Aspectos teóricos y metodológicos de la crítica del discurso y del análisis de dispositivos, en Wodak, Ruth y Meyer, Michael (ed.). Métodos de análisis crítico del discurso, Gedisa, Barcelona. 
Lewkowicz, Ignacio. (2006), Pensar sin Estado. La subjetividad en la era de la fluidez, Paidós, Buenos Aires.

Martín Serrano, Manuel. (1986), La producción social de comunicación, Alianza, Madrid.

Negri, Antonio y Cocco, Giuseppe. (2006), Global. Biopoder y luchas en una América Latina globalizada, Paidós, Buenos Aires.

Pintos, Juan Luis. (1994), “Más allá de la ideología. La construcción de la plausibilidad a través de los imaginarios sociales”, en M. A. Santos (Ed.), La educación en perspectiva, Universidad de Compostela, pp. 689-699.

Idem (2005), “Comunicación, construcción de la realidad e imaginarios sociales”, en Revista Utopía y Praxis Latinoamericana. Año 10, N²9, pp 37-65.

Schuster, Federico. (2005), "Las protestas sociales y el estudio de la acción colectiva”, en Schuster, Federico y otros (comps.) Tomar la palabra. Estudios sobre protesta social y acción colectiva en la Argentina contemporánea, Prometeo, Buenos Aires.

Scribano, Adrián y Schuster, Federico. (2004), "Protesta social en la Argentina de 2001: entre la normalidad y la ruptura”, en Medio Ambiente y Urbanización, Vol. 60, N 1, pp. 5-12.

Thompson, John .B. (1998), Los media y la modernidad. Una teoría de los medios de comunicación, Paidós, Barcelona.

Van Dijk, Teun A. (1997), Racismo y análisis crítico de los medios, Paidós, Barcelona.

Recibido: 23.08.2010

Aceptado: 25.10.2012 